\title{
NACA 2009 CONFERENCE FEEDBACK
}

The 2009 NACA Conference was held on the lush banks of the Vaal River at the Emerald Casino in Vanderbijlpark from 14 to 16 October. With over 200 delegates and 16 exhibitors, the conference was an undoubted success.

As the NACA conference followed on directly from the Department of Environment's $4^{\text {th }}$ Air Quality Control Governance Lekgotla, we were given immediate feedback on the deliberations. Mr Peter Lukey, the Chief Director: Air Quality Management and Climate Change Mitigation, outlined the latest regulatory developments, as well as future plans. One of the key developments is the implementation of, and government's readiness for, the new atmospheric emission licensing regime as this function is now delegated to municipal and provincial authorities. Other key developments in the past year included legislation on ambient air quality standards, listed activities and their associated minimum emission standards, and model air quality management bylaws. Some of the future plans for DEA include the declaration of additional priority pollutants (carbon dioxide, methane, nitrous oxide), and the intention to declare motor vehicles and small boilers as controlled emitters.

The first keynote speaker, Dr Pieter Aucamp, was instrumental in phasing out ozone-depleting substances in South Africa. Dr Aucamp shared his considerable experience with the audience as he outlined the process of international agreements, citing his experience with the Montreal Protocol and the Vienna Convention on the reduction of ozonedepleting substances.

On the second day of the conference, Professor Kobus Pienaar, Dean of the Faculty of Science at the University of the North West, alerted the audience to key uncertainties in climate change predictions in his keynote address. He illustrated how features such as variation in the earth's orbit, the effect of aerosol particles and solar activity could change the amount of incoming solar radiation, thereby affecting our Earth's temperature. Despite these uncertainties, Prof. Pienaar nevertheless made it clear that carbon resources are being exploited at an unsustainable rate, and immediate action is required.

A total of 30 scientific papers were presented, along with 7 posters. The standard of the papers was extremely high, making it rather a challenge to select the recipients of the best paper, best student paper and best poster awards. These were:

Best paper:

- Micky Josipovic, HJ Annegarn, GD Fourie, M Zunckel, MA Kneen: "Comparisons Of Meso-Scale Air Pollution Dispersion Modelling Of $\mathrm{SO}_{2}, \mathrm{NO}_{2}$ and $\mathrm{O}_{3}$ Using Regional-Scale Monitoring Results"

Best Student Papers (shared):

- Shaazia Bhailall, Stuart Piketh, Neville Smith and Jean Bogner for "Subsurface Gas Generation At A Landfill In Johannesburg" , and

- Sholo Phakedi and Harold Annegarn for their paper "Population Exposure To Cyanide Vapour From Gold Mine Tailings Dams".

Best poster:

- Baagi T. Mmereki, Chubashini Shunthirasingham, Catherine E. Oyiliagu, Ying D. Lei, Frank Wania, Todd Gouin, Wellington Masamba : "Dispersal Of Organochlorine Pesticides In Arid Regions: A Survey Of Concentration Gradients In The Soils And Atmosphere OfBotswana.

The Individual prize in the 2009 NACA Golf Day was won by Derrick Murray, with lan Naidoo and Jan Potgieter placed second and third respectively. First place in the 4-ball alliance was taken by the team of Mark Baird, Derrick Murray, Jan Potgieter and Ian Naidoo.

As always, we extend grateful thanks to the sponsors on whose support we rely - Department of Environment Affairs, ECOSERV - Member of the SGS Group, ENGEN, ESKOM, EXXARO and the North West Air Pollution Control Forum. The Golf Day was sponsored by Ecoserv, with SI Analytics donating prizes.

The 2010 NACA Conference and Golf Day will be held in Polokwane at The Ranch Hotel from 13 to 15 October, with the theme "Air Quality - Bridging the Gap". We look forward to welcoming you there! 